\title{
Chromosome painting to locate genes for drought resistance transferred from Festuca arundinacea into Lolium multiflorum
}

\author{
M. W. HUMPHREYS* \& I. PASAKINSKIENE $\dagger$ \\ Institute of Grassland and Environmental Research, Plas Gogerddan, Aberystwyth, Dyfed SY23 3EB, U.K.
}

\begin{abstract}
Genomic in situ hybridization (GISH) on mitotic chromosome preparations of two diploid Lolium multiflorum-like drought-resistant plants derived from a L. multiflorum $\times$ Festuca arundinacea hybrid is described. With $F$. arundinacea DNA as probe, each introgression line was found to carry a single Festuca recombinant chromosome segment. In both plants, the introgressed Festuca chromosome segment was on the long arm of chromosome 2 of the $L$. multiflorum-like hybrid derivative. A DNA probe of $F$. pratensis, which is one of the progenitor species of $F$. arundinacea, hybridized with the introgressed $F$. arundinacea chromosome segment. It is likely that genes that confer drought resistance have been transferred from the $F$. pratensis subgenome of $F$. arundinacea to $L$. multiflorum. It follows that the $F$. pratensis chromosome in $F$. arundinacea which is homoeologous to chromosome 2 in L. multiflorum carries genes for drought resistance.
\end{abstract}

Keywords: chromosome 2, drought resistance, genomic in situ hybridization, introgression lines, Lolium-Festuca.

\section{Introduction}

Within the Lolium/Festuca complex the combination of Festuca arundinacea and Lolium multiflorum has been claimed to offer the greatest number of complementary characters (Breese et al., 1981). Festuca arundinacea has a wider distribution than $L$. multiflorum with superior persistency, and better ability to withstand extremes of temperature and water availability. However, compared with Lolium it has poor seedling vigour, slower establishment and lower nutritive value. Lolium and Festuca spp. may readily be hybridized and thus there are opportunities for gene transfer between the two genera. Indeed, a backcross breeding programme for the effective transfer of $F$. arundinacea genes into $L$. multiflorum has been developed (Humphreys, 1989). This involved the use of pentaploid hybrids formed by the hybridization of synthetic autotetraploid $L$. multiflorum $(2 n=4 \mathrm{x}=28)$ and $F$ arundinacea $(2 n=6 x=42)$.

Diploid Lolium-like derivatives $(2 n=2 \mathrm{x}=14)$ of this backcrossing programme were assessed for

* Correspondence.

$\dagger$ Present address: Lithuanian Institute of Agriculture, 5051 Dotnuva-Akademija, Kedainiai, Lithuania. drought resistance (Humphreys \& Thomas, 1993). A low frequency ( 3 per cent) of the plants was shown to have drought resistance equivalent to that of $F$. arundinacea. Moreover, the drought resistance was shown to be inherited as it was maintained in subsequent generations (Thomas et al., 1995).

The success in confirming the phylogeny of $F$. arundinacea by Humphreys et al. (1995) using genomic in situ hybridization (GISH) provides the means whereby the origin of any introgressed chromosome segment of $F$. arundinacea can be determined. The hexaploid Festuca species was shown to have been derived from the hybridization of diploid $F$. pratensis and tetraploid $F$. glaucescens. Chromosomes and chromosome segments of the progenitor Festuca species can be distinguished both from each other and from Lolium chromosomes (Humphreys, 1995).

This paper describes GISH using DNA from $F$. arundinacea and one of its progenitors, $F$. pratensis, as probe on mitotic chromosome preparations of two drought-resistant $L$. multiflorum-like plants derived from the backcross breeding programme described above. The location of alien Festuca introgressions and their possible origins within the genome of $F$. arundinacea is discussed. 


\section{Materials and methods}

The backcross breeding programme was described by Humphreys (1989) and by Humphreys \& Thomas (1993) and is summarized in Fig. 1.

Two drought-resistant $L$. multiflorum introgression lines, $86 / 3 / 20$ and $103 / 10 / 29$, were randomly selected from the above backcrossing programme. The two drought-resistant lines were derived from different Lolium and $\mathrm{BC} 1$ parents.

GISH was carried out on mitotic chromosome preparations of the two drought-resistant $L$. multiflorum introgression lines, $86 / 3 / 20$ and $103 / 10 / 29$. The procedure was as described by Thomas et al. (1994). Total genomic DNA of $F$. arundinacea, and $F$. pratensis labelled with rhodamine-dUTP, was used as probe at $100 \mathrm{ng}$. per slide. Sonicated L. multiflorum DNA at $\times 40$ probe concentration $(4 \mu \mathrm{g}$ per slide) was used as blocker in the hybridization mixture to enhance species-specific fescue DNA hybridization on the chromosome preparations. All preparations were counterstained with DAPI. Images of the introgressed fescue chromosome segments were captured digitally, in monochrome, with a CoolView CCD camera and Apple Macintosh computer using software by Improvision. The monochrome rhodamine images were given false red colours. They were then combined with images made separately using DAPI as counterstain which in turn was given a false blue colour.

\section{Results}

The two drought-resistant introgression lines, $86 / 3 / 20$ and $103 / 10 / 29$ are both diploid $(2 n=2 x=14)$. Each contained a single introgressed Festuca chromosome segment (Fig. 2). The size of the introgressed chromosome segments differed between the two drought-resistant lines with $103 / 10 / 29$ containing a larger fescue segment than $86 / 3 / 20$. Despite the difference in size of the introgressed segments, they would both appear to overlap

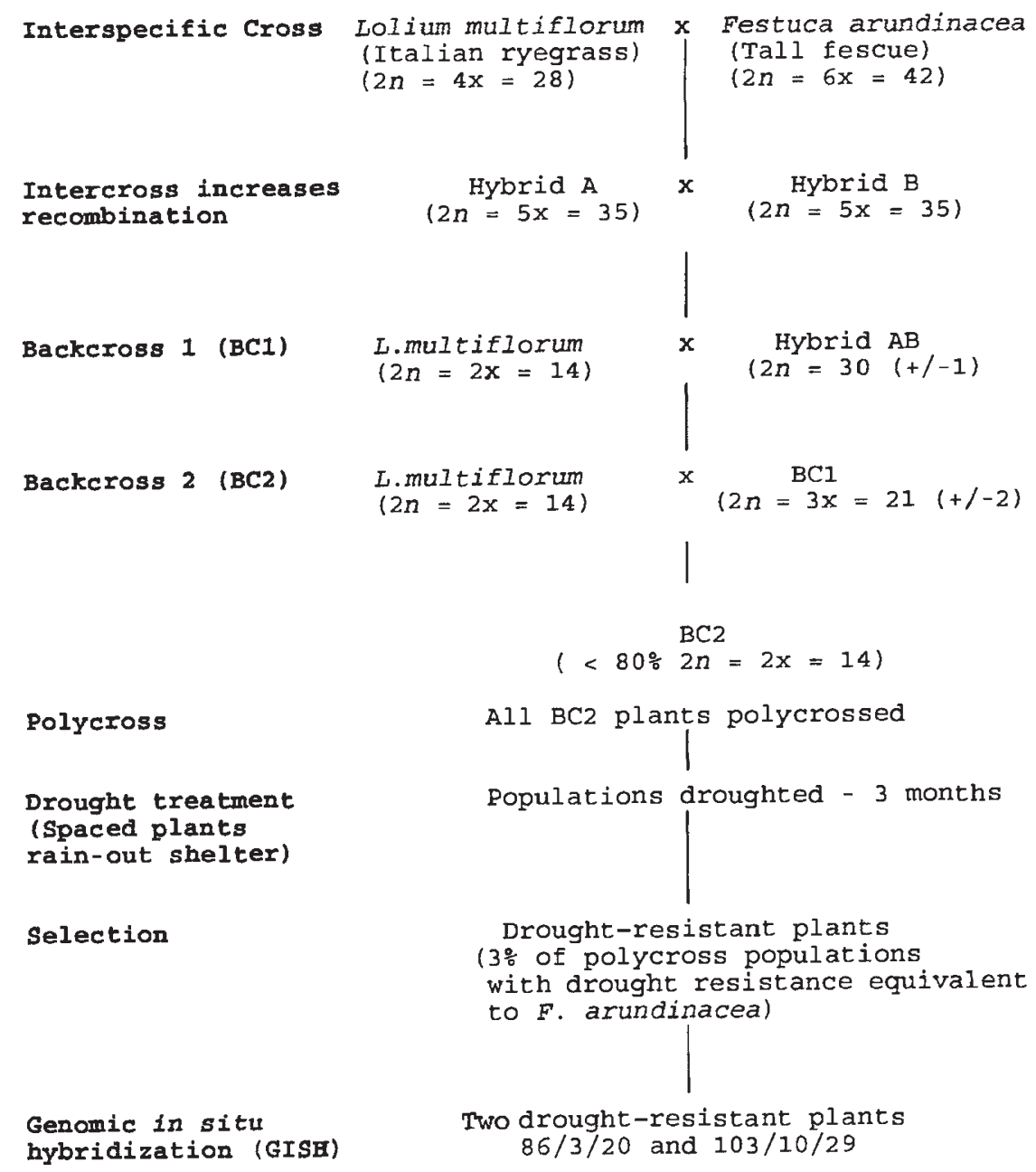

Fig. 1 The breeding programme for the transfer of drought resistance from Festuca arundinacea to Lolium multiflorum.

Genomic in situ hybridization (GISE) 

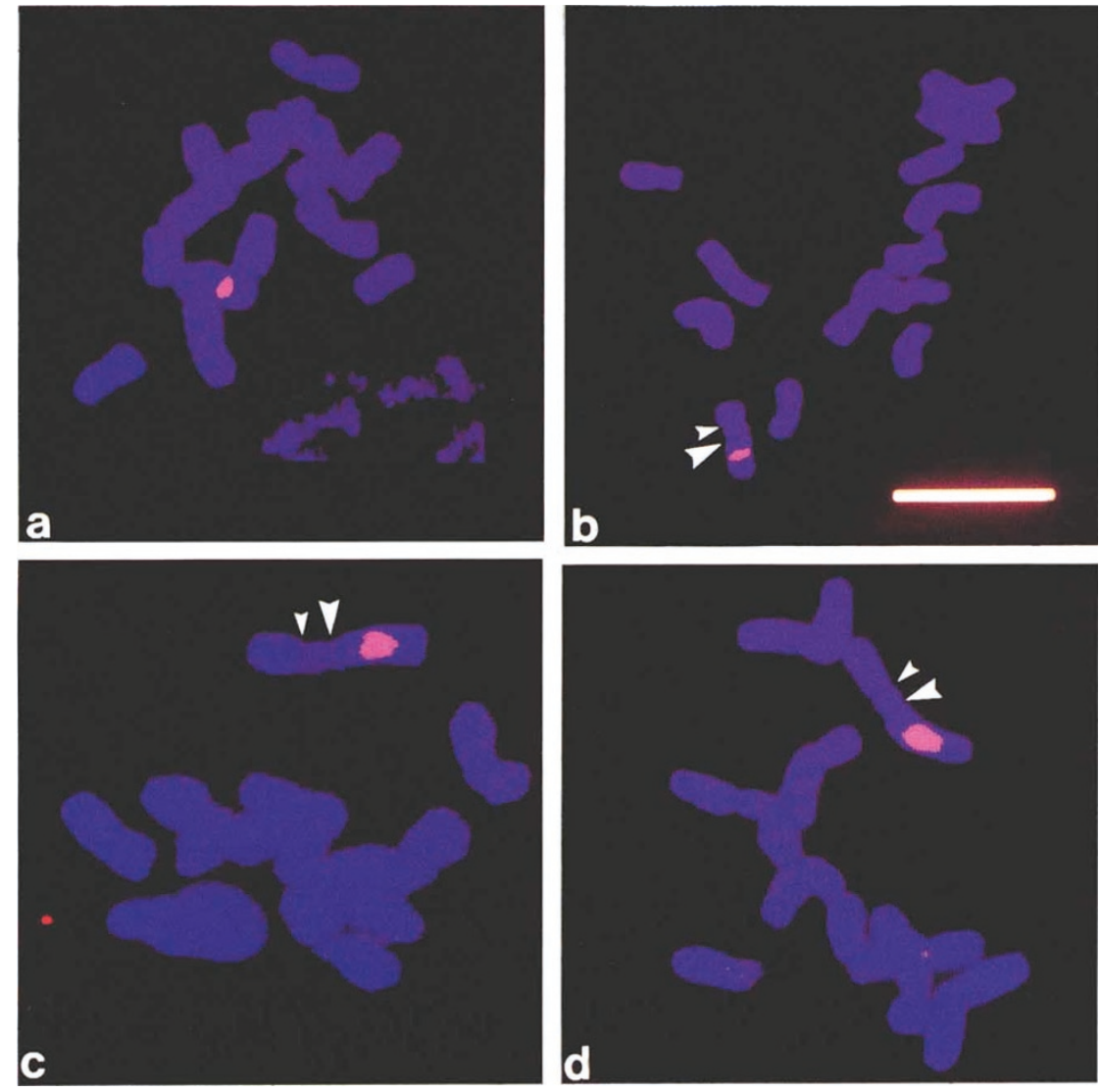

Fig. 2 Genomic in situ hybridization (GISH) on mitotic chromosome preparations of drought-resistant $L$. multiflorum $(2 \mathrm{x})$ lines 86/3/20 and $103 / 10 / 29(2 n=2 x=14)$ derived from a Lolium multiflorum $(4 \mathrm{x}) \times$ Festuca arundinacea (6x) hybrid. (a) 86/3/20 with $F$. arundinacea and (b) with $F$. pratensis total genomic DNA as probe; (c) $103 / 10 / 29$ with $F$. arundinacea and (d) F. pratensis total genomic DNA as probe. Cells (b) and (d) are incomplete cells chosen to illustrate the introgressed chromosome segment on chromosome 2. Primary (large arrowhead) and secondary (small arrowhead) constrictions on L. multiflorum chromosome 2 are indicated.

$\mathrm{Bar}=10 \mu \mathrm{m}$. on the same $L$. multiflorum chromosome. In both cases the introgressed fescue segment was interstitially located on the long arm of satellite chromosome 2 (Lewis et al., 1980). As the introgressed Festuca chromosome segment in both drought-resistant selection lines had flanking Lolium DNA on either side, at least two previous recombination events must have occurred in both involving the $L$. multiflorum chromosome 2. Despite the two introgression lines being derived from different $\mathrm{BC} 1$ parents, it is possible that they originated following only one interspecific recombination event early in the backcross breeding programme. In this case, the smaller introgressed Festuca chromosome segment seen in line 86/3/20 would have arisen following recombination with a complete $L$. multiflorum chromosome 2 at a site on the original introgressed Festuca chromosome segment observed in 103/10/29.

\section{Introgression line $86 / 3 / 20$}

A narrow introgressed Festuca chromosome segment was seen in Fig. 2(a) when probed with total genomic DNA probe of $F$. arundinacea. The chromosome orientation was such that the L. multiflorum chromosome carrying the introgressed segment could not be identified. However, when a mitotic chromosome preparation of the same genotype was probed with a total genomic DNA probe of $F$. pratensis (Fig. 2b), a single narrow Festuca segment was observed approximately centrally in the long arm of a large satellite chromosome identified by its gross morphology as chromosome 2.

\section{Introgression line 103/10/29}

A large introgressed Festuca chromosome segment is seen in Fig. 2(c) which has been probed with total genomic DNA probe of $F$ arundinacea. The introgressed chromosome segment occupies a central position on the long arm of a satellite chromosome, again identified as chromosome 2 . The introgressed Festuca chromosome segment occupied approximately half of the long arm of chromosome 2. A mitotic chromosome preparation of the same genotype was subsequently probed with a total genomic DNA probe of $F$. pratensis (Fig. 2d). The introgressed $F$. arundinacea chromosome segment hybridized with the $F$. pratensis DNA probe.

(C) The Genetical Society of Great Britain, Heredity, 77, 530-534. 


\section{Discussion}

The results describe the characterization of two diploid drought-resistant $L$. multiflorum plants using GISH. Each Lolium plant was derived from a backcrossing programme involving as a starting point a pentaploid hybrid between $L$. multiflorum and $F$. arundinacea. Both drought-resistant lines carry a single introgressed Festuca chromosome segment. Despite differences in the size of the introgressed Festuca segment they apparently occupy overlapping positions on the long arm of a large satellite chromosome identified as chromosome 2 (see Lewis et al., 1980).

Lewis et al. (1980) described how the isozyme marker glutamate oxaloacetate transaminase (GOT/3) was located on chromosome 2 of $L$. multiflorum. Current investigations by the Cytogenetics Group at IGER will confirm the precise position of the $G O T / 3$ locus. If the $G O T / 3$ locus is located on the long arm of chromosome 2 in L. multiflorum, then this locus could be used to assist the selection of genes for drought resistance in a breeding programme. The current development of molecular marker systems such as RFLPs and RAPDs in Lolium (Hayward et al., 1994) has identified other marker loci linked to GOT/3 and therefore also located on chromosome 2 . As the numbers of these markers increase, it should be possible closely to tag and select genes for drought resistance in any introgression programme and exclude individuals with additional and possible deleterious Lolium/Festuca gene combinations.

The recent determination of the progenitors of hexaploid $F$. arundinacea using GISH (Humphreys $e t$ al., 1995) confirmed other research workers' (e.g. Chandrasekharan \& Thomas, 1971) conclusions that the polyploid species was derived from a hybrid between $F$. pratensis $(2 \mathrm{x})$ and $F$. glaucescens $(4 \mathrm{x})$. Genes which determine drought resistance in $F$. arundinacea may be found in all three subgenomes of the polyploid species. Humphreys \& Ghesquière (1994) demonstrated using an isozyme marker, phosphoglucoisomerase (PGI/2), that it was possible to obtain recombinants in $L$. multiflorum from each of the three subgenomes which make up $F$ arundinacea. However, recombinants between the PGI/2-labelled chromosome of one subgenome of $F$. arundinacea (found to be $F$. pratensis (Humphreys, 1995)) and its homoeologous L. multiflorum partner were obtained at twice the frequency of those involving Lolium and the other two Festuca genomes.

The higher frequency of recombination between $L$. multiflorum and the $F$. pratensis genome of $F$. arundinacea compared with that obtained from the $F$. glaucescens genomes, makes it more likely that the drought resistance transferred from the hexaploid fescue species was derived from the $F$. pratensis subgenome of $F$. arundinacea. The detection of the introgressed Festuca chromosome segments in the two drought-resistant plants, by $F$. pratensis labelled total genomic DNA probe, would appear to support this conclusion. Humphreys (1995) found GISH between DNA of $F$. pratensis and $F$. glaucescens to be very species-specific with little or no cross-hybridization between the DNA of the two Festuca species. It is unlikely that a total genomic DNA probe of $F$. pratensis would hybridize with the introgressed $F$. arundinacea chromosome segments if they were derived from either of the $F$. glaucescens subgenomes of the hexaploid Festuca species.

The genotypes of $86 / 3 / 24$ and $103 / 10 / 29$, with the exception of the recombinant Festuca chromosome segments present on chromosome 2, appear identical to that of L. multiflorum. Both introgression lines have drought resistance which is significantly greater (Humphreys \& Thomas, 1993) than that found in cultivars Tribune and RvP which were used as recurrent $L$. multiflorum parents in the backcross breeding programme. We propose that Festuca genes present on chromosome 2 in the two introgression lines have led to the increased drought resistance of L. multiflorum. A test-cross between the introgression lines and $L$. multiflorum will be required to confirm whether our expectations are valid. The effect of presence or absence of the introgressed Festuca genes and their relationship with drought resistance in $L$. multiflorum will then be confirmed.

We further propose that the chromosome of $F$. pratensis in $F$. arundinacea which is homoeologous to chromosome 2 in $L$. multiflorum is likely to carry genes for drought resistance.

Most Lolium/Festuca PGI/2 recombinants recovered in the backcrossing programme between $L$. multiflorum and the pentaploid hybrid between $L$. multiflorum and $F$. arundinacea involved the $F$. pratensis genome (Humphreys \& Ghesquière, 1994). However, interspecific recombination between $F$. pratensis and L. multiflorum at the PGI/2 locus at around 10 per cent is only half that obtained when L. multiflorum is backcrossed onto the triploid hybrid between $L$. multiflorum $(4 \mathrm{x})$ and $F$. pratensis (2x) (Humphreys, unpublished data). If the genes for drought resistance found in the $F$ pratensis subgenome of $F$ arundinacea are conserved in natural populations of $F$. pratensis (2x), then it may well be that introgression of drought resistance genes from Festuca spp. into Lolium may be better

(c) The Genetical Society of Great Britain, Heredity, 77, 530-534. 
accomplished directly by hybridizing $L$. multiflorum with $F$. pratensis rather than with the polyploid fescue.

Although many genes on different Festuca chromosomes may determine complex physiological processes which convey characters such as drought or cold resistance, certain genes will presumably have greater influence. By the identification and selection of the major drought or cold resistance determining genes in Festuca spp., the major components of these systems may be transferred into Lolium without undue loss of desirable traits in the host germplasm.

\section{Acknowledgements}

The authors acknowledge the financial support of BBSRC which enabled the carrying out of this research and The British Council for partly funding Dr Pasakinskiene's sabbatical at IGER.

\section{References}

BREESE, E. L., LEWIS, E. J. AND EVANS, G. M. 1981. Interspecies hybrids and polyploidy. Phil. Trans. R. Soc. B, 292, 487-497.

CHANDRASEkHARAN, P. AND ThOMAS, H. 1971. Studies in Festuca V. Cytogenetic relationships between species of bovinae and scariosae. Z. PflZücht., 65, 353-354.

HAYWARD, M. D., MCADAM, N. J., JONES, J. G., EVANS, C., EVANS, G. M., FORSTER, J. W. ET AL. 1994. Genetic markers and the selection of quantitative traits in forage grasses. Euphytica, 77, 269-275.

HUMPHREYS, M. W. 1989. The controlled introgression of
Festuca arundinacea genes into Lolium multiflorum. Euphytica, 42, 105-116.

HUMPHREYS, M. w. 1995. Gene Introgression Following Intergeneric Hybridization Within the Lolium/Festuca Complex. Ph.D. Thesis, University of Wales.

HUMPHREYS, M. W. AND GHESQUIERE, M. 1994. Assessing success in gene transfer between Lolium multiflorum and Festuca arundinacea. Euphytica, 77, 283-289.

HUMPHREYS, M. W. AND THOMAS, H. 1993. Improved drought resistance in introgression lines derived from Lolium multiflorum $\times$ Festuca arundinacea hybrids. $P l$. Breed., 111, 155-161.

HUMPHREYS, M. W., THOMAS, H. M., MORGAN, W. G., MEREDITH, M. R., HARPER, J. A., THOMAS, H. ET AL. 1995. Discriminating the ancestral progenitors of hexaploid Festuca arundinacea using genomic in situ hybridization. Heredity, 75, 171-174.

LEWIS, E. J., HUMPHREYS, M. W. AND CATON, M. P. 1980. Chromosome location of two isozyme loci in Lolium perenne using primary trisomics. Theor. Appl. Genet., 57, 237-239.

THOMAS, H. 1994. Diversity between and within temperate forage species in drought resistance, water use and related physiological responses. Proc. Asps. of Appl. Biol., 38, 47-55.

THOMAS, H., HUMPHREYS, M. W., GHESQUIÈRE, M., HUMPHREYS, M. O. AND MOUSSET, C. 1995. Introgression of drought resistance in Lolium by introgression from Festuca. Proceedings of the InterDrought 95 Congress, Montpellier, France.

THOMAS, H. M., MORGAN, W. G., MEREDITH, M. R., HUMPHREYS, M. W., THOMAS, H. AND LEGGETT, J. M. 1994. Identification of parental and recombined chromosomes of Lolium multiflorum $\times$ Festuca pratensis by genomic in situ hybridization. Theor. Appl. Genet., 88, 909-913. 